\title{
Enhancing the effectiveness of tobacco package warning labels: a social psychological perspective
}

\section{E J Strahan, K White, G T Fong, L R Fabrigar, M P Zanna, R Cameron}

See end of article for
authors' affiliations
$\ldots \ldots \ldots \ldots \ldots \ldots \ldots$
Correspondence to:
Geoffrey T Fong,
Department of Psychology,
University of Waterloo,
200 University Avenue
West, Waterloo, Ontario,
N2L 3G1, Canada;
gfong@
watarts.uwaterloo.ca

Received 17 July 2001 and revision requested 8 October 2001.

Accepted 1 March 2002
Tobacco Control 2002;11:183-190

\begin{abstract}
Objective: To outline social psychological principles that could influence the psychosocial and behavioural effects of tobacco warning labels, and to inform the development of more effective tobacco warning labels.

Data sources: Psyclnfo and Medline literature searches and expert guided selection of principles and theories in social psychology and of tobacco warning labels, including articles, books, and reports.

Conclusions: Tobacco warning labels represent a potentially effective method of influencing attitudes and behaviours. This review describes social psychological principles that could be used to guide the creation of more effective warning labels. The potential value of incorporating warning labels into a broader public health education campaign is discussed, and directions for future research are suggested.
\end{abstract}

their findings in terms of the social psychological principles that we outline in this paper. Furthermore, a search of Medline and PsycInfo databases for "social psychology" and "warning labels" yielded no items. Thus, the articles and reports cited in this conceptual review article came from an expert guided search of the social psychological literature. tion of Canada's new graphic warning labels in December 2000 has prompted other countries to review their requirements and may lead to new warning labels in many of those countries. Hence, it seems timely to consider methods that could be employed to enhance the effectiveness of tobacco warning labels.

This paper will outline various social psychological principles that could be used to guide the creation of effective tobacco warning labels. In addition, we will discuss the need to integrate tobacco warning labels with other anti-smoking efforts (for example, point-of-sale ads, television commercials, etc). Finally, this paper will outline the value of future systematic research in the area of tobacco warning labels. We are aware that policy makers are often under constraints as to what types of messages they can implement (for example, some countries may allow only health oriented messages on their warning labels, as is currently the case in Canada under the 1997 Tobacco Act). We conceptualise the psychological principles outlined here as being suggestions that policy makers can selectively choose from depending on their particular constraints (for example, whether the warning messages must be health related), or their goals (for example, whether they are targeting a specific demographic group).

We began this conceptual review by using our expertise to identify the principles and research domains from social psychology that we felt were applicable to understanding the possible effects of tobacco warning labels. We reviewed the social psychological literature on persuasion, fear appeals, and various social psychological theories of behaviour change (for example, theory of reasoned action/planned behaviour). We then conducted an extensive review of the research literature on warning labels, which included a review of all the sources cited in a literature review by Mitchell, ${ }^{2}$ as well as other sources, to identify articles, chapters, reports and other material that were directly or indirectly relevant to the social psychological literature. We did not find any articles that cast

\section{SOCIAL PSYCHOLOGICAL PRINCIPLES FOR ENHANCING THE EFFECTIVENESS OF WARNING LABELS}

Over the past 50 years, a vast body of social psychological research regarding the processes and principles that affect attitude and behaviour change has accumulated..$^{3-5}$ A number of basic principles for enhancing the effectiveness of warning labels can be derived from this research. These principles can be divided into two categories. Content principles refer to features of the message content itself that make the message more effective. Process principles refer to design features (for example, stylistic features) that make the message more effective. Both categories of principles can be used to inform the design of warning labels.

\section{Content principles}

Currently, warning labels that appear on tobacco packages typically consist of simple statements about the health risks of smoking (for example, "Smoking can kill you", "Smoking causes lung cancer"). Although pointing out the health risks of smoking may be beneficial, it is clear from the research on attitudes and persuasion that the sole focus on negative health risks may be too narrow. ${ }^{6}$ The social psychological research on attitudes and persuasion suggests several general content principles that could guide the creation of new warning labels.

Promote attitudes and beliefs towards alternative behaviours

The core principle here is quite straightforward: messages are more likely to be persuasive if they not only promote negative attitudes toward an undesired behaviour (for example, smoking), but also promote positive attitudes toward a mutually exclusive desired behaviour (for example, quitting smoking). 
Research indicates that a person's attitude toward smoking is not the exact opposite of his/her attitude toward quitting smoking. ${ }^{7}$ For example, a smoker might have a negative attitude toward smoking and might believe it is unhealthy and dangerous to smoke, but if this person's attitude and beliefs about quitting smoking are even more negative, they will continue to smoke.

This research suggests that warning labels would be more effective if they created a strong positive attitude toward quitting, in addition to promoting a strong negative attitude towards continued smoking. Incorporating positive, factual messages about the benefits of quitting could represent a simple, but important, improvement. For example, some labels could stress the immediate health benefits of quitting. One of the inside messages introduced as part of the new Canadian warning labels states that "Quitting smoking reduces your chance of having a heart attack". Other labels could stress the financial benefits of quitting (for example, "If you smoke two packs a day, quitting will save you over $\$ 3500$ in the next year").*

\section{Utilise gain-framed messages}

The importance of incorporating positive information into smoking labels is further supported by research on gainframed versus loss-framed messages. ${ }^{8}{ }^{9}$ Health messages can focus on the negative consequences of continuing to engage in a health compromising behaviour (loss-framed messages) or they can focus on the positive consequences of refraining from a health compromising behaviour (gain-framed messages). Warning labels, as well as most anti-smoking campaigns, focus nearly exclusively on loss-framed messages. ${ }^{111}$

Past research suggests that whether loss or gain-framed messages are more effective depends on various factors, such as whether respondents are motivated to engage in effortful processing $^{12}$ and level of self-efficacy. ${ }^{13}$ More recent evidence indicates that loss-framed messages appear to be successful in promoting behaviours related to early detection, such as clinical skin examinations, ${ }^{14}$ mammography screening, ${ }^{15}$ breast self examination, ${ }^{13}$ and HIV testing. ${ }^{16}$ In contrast, gain-framed messages have been found to influence prevention related behaviours such as sunscreen use, ${ }^{17}$ preference for surgical procedures, ${ }^{18-21}$ and engaging in regular physical exercise. ${ }^{22}$ Because quitting smoking is a preventive health behaviour, these studies suggest that messages designed to encourage smokers to quit might be more effective if they were framed in terms of gains rather than losses.

One recent study directly addresses the effects of gainframed versus loss-framed messages in smoking. Schneider and colleagues ${ }^{11}$ found that gain-framed health messages (for example, "Quitting smoking reduces your chances of premature death and illness") were more effective than the same messages rewritten so that they were loss-framed (for example, "Smoking increases your chances of premature death and illness") in changing smoking related beliefs, attitudes, and behaviours.

It should be noted that this research on framing cannot be used to conclude that gain-framed messages are effective and loss-framed messages are not. Rather, it suggests that gain-framed messages may be more effective in certain settings than loss-framed messages. A second qualifying comment is warranted here. The research on framing does not conclude that gain-framed messages are superior to lossframed messages when the gain-framed message covers a different topic than a loss-framed message. For example, it cannot predict that a gain-framed message such as "you'll experience greater self-esteem if you quit smoking" will be

* Calculation based on cigarette packages costing $\$ 5.00$.

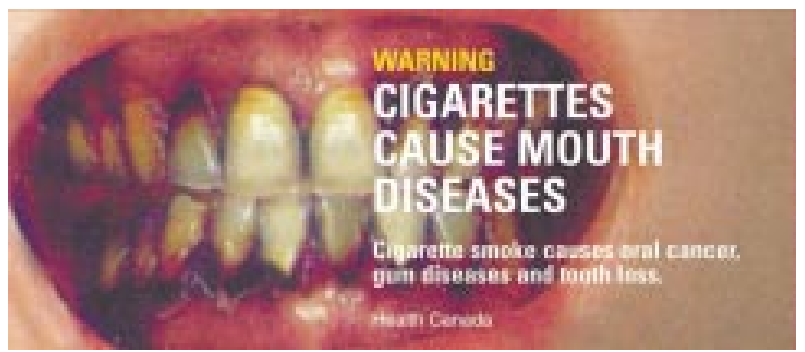

Figure 1 Canadian package warning label that may invoke fear.

more effective than a loss-framed message such as "if you keep smoking, you will be many times more likely to get lung cancer" because of differences in content. What the research does suggest is that even health messages on warning labels, which are currently exclusively framed in terms of losses, might be more effective if some of the messages were reframed in terms of gains. In short, it may be effective to use multiple messages that focus on the both the benefits of quitting and the costs of smoking.

There is one class of loss-framed messages that is of particular relevance for warning labels. These are those that involve fear appeals. For about 50 years, researchers and practitioners alike have conducted research demonstrating the effectiveness of fear appeals in influencing health relevant attitudes and behaviour. ${ }^{63-26}$ Out of the literature on fear appeals has emerged some general conclusions about the conditions under which fear appeals are most likely to be effective. In a recent meta-analysis and literature review of the research on fear appeals, Witte and Allen ${ }^{26}$ drew several conclusions, including two that are most relevant here: (1) fear appeals can be effective in increasing healthy behaviour and decreasing unhealthy behaviour; and (2) fear appeals are effective to the extent that they are accompanied by efficacy messages - that is, messages that provide information about how to avoid the threat that is highlighted by the fear appeal.

Thus, loss-framed messages used on warning labels are more likely to be effective if: (a) they are combined with gainframed messages (emphasising that quitting is possible and beneficial); and (b) they advise the reader how to quit, or where to get help. The new Canadian warning labels are consistent with these recommendations: the new warning labels consist of an outside message accompanied by a vivid photograph that may invoke fear (fig 1 ), and 16 rotated inside messages (fig 2), many of which provide a strong efficacy message- that is, information about actions one can take to avoid the health threat depicted on the outside label. Further research should clarify the ways in which combinations of both loss-framed and gain-framed messages influence smoking attitudes, beliefs, and behaviours.

\section{Emphasise subjective norms}

Subjective norms and social approval have a strong influence on health behaviour. We are more likely to perform a behaviour if we believe that the behaviour is valued or expected within our reference group. We tend to accommodate the expectations of important people in our lives. ${ }^{27}$ This principle implies that smokers who are contemplating quitting may find the impulse to quit counteracted by perceptions that smoking is the norm within their reference group.

There is evidence that subjective norms predict intentions to perform health behaviours. ${ }^{28-32}$ For example, Finlay and colleagues $^{30}$ found that subjective norms predicted behavioural intentions across a wide range of health behaviours, such as avoiding risky sexual behaviour, paying attention to health related advice, and taking medication as prescribed. Most importantly, subjective norms have been found to predict smoking intentions and behaviour. ${ }^{33}$ 


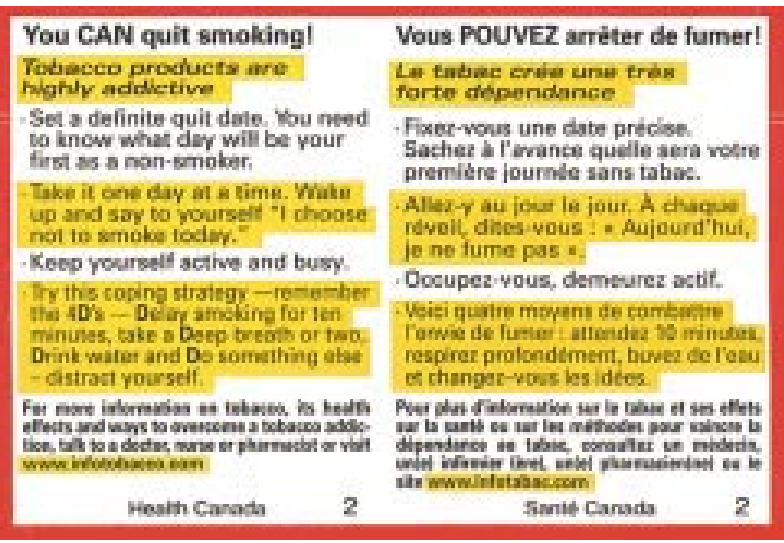

Figure 2 Canadian package warning label with strong efficacy message.

The research on subjective norms suggests that warning labels might be more effective if they conveyed credible messages indicating that significant referent groups (for example, children, friends, physicians) were strongly in support of cessation. Polling data could be used to provide support for subjective norm based appeals. For instance, one could determine the percentage of family members and friends that want their loved ones to quit smoking and then incorporate this information into a message (for example, " $85 \%$ of family members surveyed want their loved ones to quit smoking").

In a related vein, labels might be more effective if they highlighted the negative social consequences of smoking (for example, "Smoking causes bad breath and yellow teeth"). van der Plight and de Vries $^{35}$ found that both smokers and non-smokers believed that smoking is bad for one's health, but only smokers believed that smoking helps people relax and, most pertinent here, that smoking fosters social interaction. Labels could present the negative social consequences of smoking to counteract smokers' perceptions that smoking facilitates social interactions.

This point might be most relevant in considering the impact of current warning labels on adolescents. The narrow focus on the health risks associated with smoking may not be optimally effective with adolescents. Adolescents are less likely than adults to value their health, and as a result, the messages may seem irrelevant to them. Furthermore, research has highlighted the role that social and self presentational reasons play in adolescent smoking. ${ }^{36}{ }^{37}$ Therefore, warning labels that focus on the negative social consequences of smoking may be more effective among adolescents than those that focus on the negative health consequences.

\section{Focus on relevant attitudes of the target group}

Different messages are relevant to different segments of the population (for example, those who smoke $v$ those at risk of initiating smoking; adolescents $v$ adults). Recent research indicates a person's three most important smoking related beliefs are better predictors of smoking behaviour than a composite of one's general smoking beliefs. ${ }^{38}$ Research that identifies important beliefs and values relevant to smoking and quitting held by target groups would, as social marketing principles suggest, be a valuable first step in designing messages of greater impact.

The social psychological literature points out that it is important not only to identify which attitudes and beliefs are important for a given group, but also the underlying reasons for those attitudes and beliefs. ${ }^{38}$ Research in this area focuses on the important question: what are the underlying functions for holding particular attitudes? Attitudes fulfil various functions, and understanding the function of the attitude provides insight into the types of messages likely to have impact. ${ }^{39} 40$

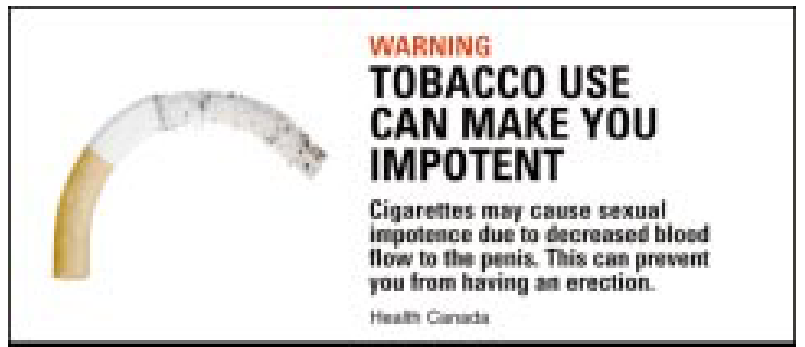

Figure 3 Canadian package warning label directed at young males.

The concept of attitude function has been studied in relation to attitudes towards victims of AIDS, ${ }^{41}$ attitudes towards homosexuals, ${ }^{42}$ attitudes towards automobiles, ${ }^{43}{ }^{44}$ and attitudes towards advertising of consumer products. ${ }^{45-52}$

As applied to smoking, this suggests that it is not only useful to know that the target group has positive attitudes towards smoking, but also to be aware of why that group has positive attitudes towards smoking. An adolescent may hold positive attitudes towards smoking because she wishes to fit in with her peers, to keep her body weight low, or because she enjoys the physiological effects of smoking. Knowledge of a particular group's attitude functions can be beneficial in the creation of appropriate and effective smoking labels. For example, it might be effective to create different labels for different brands, in much the same way as tobacco companies create different brand images for different brands (for example, placing a warning label about the dangers of impotence on the package of a brand that is marketed to young males (fig $3)$ ). This suggestion is similar in ways to the process of market segmentation that is prevalent in any marketing endeavour. This segmentation process may be profitably guided by applying the findings in the social psychological literature to warning labels (for example, in the application of fear appeals ${ }^{53}$ ). Finally, it seems likely that rotating multiple warning label messages that address these different attitude functions will be an effective strategy.

Increase perceived self efficacy

People are more likely to attempt to change their behaviour (for example, quit smoking) if they believe they can succeed-that is, if they have a high level of self efficacy ${ }^{54}$ or perceived behavioural control. ${ }^{29} 55$ Those with higher levels of self efficacy are more likely to alter successfully a wide range of health behaviours, including AIDS risk behaviours, ${ }^{56}$ exercise maintenance and relapse, ${ }^{57-59}$ alcohol consumption, ${ }^{60}{ }^{61}$ and dietary intake. ${ }^{62}$

Smokers who are high in self efficacy have a greater chance of entering treatment to quit smoking and have a greater chance of success than those who are low in self efficacy. ${ }^{63}$ Bandura $^{64}$ has described several strategies for enhancing self efficacy. The effectiveness of warning labels may be considerably enhanced by reinforcing people's beliefs that they are capable of quitting smoking. Labels could provide some general statements about quitting efficacy (for example, "You can quit smoking and reduce your risk of lung cancer") or specific information about the process of quitting that would be encouraging (for example, "Smokers who quit tended to try a number of times before they succeeded, so keep trying!"). These kinds of messages would also serve to enhance outcome efficacy (or behavioural beliefs, in the theory of planned behaviour ${ }^{55}$ ).

Another promising avenue for enhancing self efficacy is to provide information about quitting. The importance of providing specific information about quitting is also highlighted by the classic literature on fear appeals in social psychology. As mentioned earlier, this research suggests that 


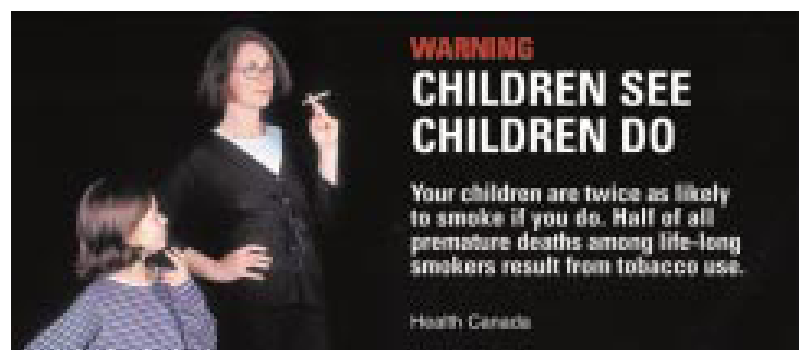

Figure 4 Canadian package warning label warning parents about their own smoking behaviour.

messages stressing the negative health consequences of smoking create fear among smokers, and that such messages may be more effective when presented in tandem with recommendations for how the negative consequences can be avoided. ${ }^{62}$ Thus, labels that provide information about quitting could enhance the effectiveness of not only the current set of warning labels that focus exclusively on negative health consequences, but also future warning labels that would focus on enhancing people's efficacy to quit. For example, the new Canadian warning labels include quit tips, efficacy messages, and a website for obtaining additional information about methods of quitting.

\section{Additional content principles}

One other factor that appears to be important is whether or not the anti-smoking label encourages interpersonal communication. For example, one recent study found that discussing a smoking campaign with someone else was predictive of positive behavioural outcomes among smokers. ${ }^{65}$ Smoking labels might profitably encourage people to talk to others about smoking. A second additional factor that is important is the ability to induce cognitive dissonance. Cognitive dissonance is an unpleasant state that is aroused when an individual has an attitude that is discrepant to a behaviour or to a new piece of information. ${ }^{66}$ For example, an anti-smoking label that makes salient to smokers that their beliefs (for example, smoking is bad for your health) and their behaviours (for example, smoking two packs of cigarettes a day) are contradictory may be an effective means of reducing smoking. Research has found that a hypocrisy manipulation which makes people aware of their dissonant beliefs can be an effective means of changing health related behaviours. ${ }^{67}$ This research suggests that warning labels could be designed to serve as a hypocrisy manipulation. For example, if smokers believe that children should not smoke and they have told their own children not to smoke, warning labels could remind smokers that their own smoking behaviour is a major cause of their own children's smoking (fig 4). This should make parents feel guilty about smoking and could ultimately lead to a decrease in smoking behaviour. In addition, labels that ask people to commit to quitting may create the need to be consistent with that commitment and may encourage quitting. ${ }^{68}$

\section{Process principles}

Whereas content principles are concerned with how the content of the labels might be changed to improve their effectiveness, process principles are concerned with the manner in which a message is presented. In many countries, the warning label is presented in a visually indistinct way. There are several ways that the presentation could be enhanced to make warning labels more effective.

One set of relevant process principles can be derived from a social psychological theory known as the elaboration likelihood model. ${ }^{5}$ A similar theoretical framework, the heuristicsystematic model, has been formulated by Chaiken ${ }^{69} 70$ and has also been applied to understanding the cognitive and social psychological principles underlying the effects of warning labels. $^{71}$

According to the elaboration likelihood model, people are sometimes persuaded as a result of thinking very carefully about the content of a message and on other occasions by considering factors that have little to do with the content of a message. When a person is both motivated and able to think carefully about a message, that person engages in extensive elaboration of the message. This process involves carefully scrutinising the merits of the arguments. Thus, a person may assess the validity of the arguments in light of what they already know, form inferences that go beyond the information presented, and perhaps even seek out additional information. When persuasion occurs as a result of extensive elaboration of a message, they are taking the so called central route to persuasion, and the persuasiveness of the message will depend on the strength of the arguments.

On other occasions, people may lack the motivation (for example, they may not see the topic as personally relevant) and/or ability (for example, they may lack sufficient knowledge about the topic or may have distractions in their environment) to elaborate carefully on a message. In such cases, they will not consider the strength of the arguments, but instead look for simple characteristics of the message or the context in which it is encountered to provide them with a basis for determining whether they should accept the message. For example, they may use the attractiveness or credibility of the persuader as a basis for deciding to accept the message. In so doing, they are taking the peripheral route to persuasion, and the persuasiveness of the message will depend not on message content, but on other features of the message, or the message context-and such non-central features can be just as persuasive.

People are exposed to warning labels under many different circumstances, some of which favour elaboration, and some of which do not. Hence, it would be wise to build features into warning labels that influence people under a wide variety of different levels of elaboration.

Colour is one way to capitalise on process principles. For instance, consider the impact of presenting warning labels in bright orange print. Orange is associated with warning and danger signs: under conditions of low elaboration, orange in labels may convey a "warning" message, independent of content, because of this sort of association. Under conditions in which people are able to examine the content of the label, but perhaps are only moderately motivated to do so, the bright colour may attract attention, and prompt them to consider the message content. Finally, with those motivated to read the message carefully, the association of orange with danger might evoke feelings congruent with the message content and thus increase message acceptability and impact.

Iconic symbolic images may also be useful for conveying persuasive messages. If a widely recognised athlete, who symbolises health and vigour, appeared on tobacco package warning labels, endorsing the anti-smoking message, this might increase the impact of the message in several ways. Under conditions of low elaboration, the image would be a peripheral cue signalling the health message independent of content. People would understand and accept the message because they like and trust the iconic figure. Under conditions of moderate elaboration, people might be more willing to read and reflect upon what this popular spokesperson has to say. Under conditions of high elaboration, positive feelings toward the spokesperson could enhance the likelihood that people would agree with the message.

Overexposure, or wear-out, is a major problem for any message that is presented many times over a period of time. When people receive a message multiple times, the message's effectiveness tends to increase over the first few exposures, but then begins to diminish over time. ${ }^{72}$ A survey conducted in the 
summer of 1999 revealed that among over 2000 Canadian adults and 746 Canadian youth aged $12-18$ years, $65 \%$ of adult smokers and $74 \%$ of youth smokers agreed that the warning labels that were introduced in 1994 were "worn-out and had lost their effectiveness". ${ }^{73}$ Other studies found that individuals exposed to newly designed warnings were significantly more likely to remember the concept of the warnings than individuals exposed to old mandated warnings. ${ }^{74}{ }^{75}$ Our review of the research on gain and loss-framed messages and on the functions of attitudes suggests that a variety of anti-smoking messages would be effective, and such a strategy would also address this overexposure problem.

Advertising campaigns have developed strategies to counteract the overexposure problem. These include changing ads and commercials by employing different variations of the same theme, promoting the products via different spokespersons, or even following people as they progress through a series of decisions or judgments involving the product. Policy makers have suggested that rotating smoking label messages may counteract the overexposure problem. ${ }^{76}$ Designing warning labels in various appropriate colours and broadening the content of the messages may help to counteract overexposure. Any method that reduces overexposure increases the likelihood that people will read the warning labels, and attracting people's attention is the first step in the influence process.

\section{INCORPORATING WARNING LABELS INTO A BROADER ANTI-SMOKING CAMPAIGN}

There are limits to what warning labels can be expected to accomplish in isolation. Warning labels are very brief messages, considerably shorter than the typical persuasive communication, and thus there are limitations to the amount of information that they can convey. Furthermore, policy constraints limit the type of information that can appear on smoking warning labels.

Warning labels might be considerably more effective if references were made to the labels as part of a broader, coordinated anti-smoking campaign. This more extensive anti-smoking campaign would not be subject to the policy constraints that the warning labels are subject to, and would thus be better positioned to employ the social psychological principles outlined above.

A multimedia campaign using many avenues for communication has the potential to persuade people using both elaborated and unelaborated channels of communication. For instance, catchy, colourful posters and labels could be used to persuade via the peripheral route, whereas more informative print ads and television commercials could be used to persuade people via the central route. Thus, people at all levels of elaboration could be reached if such an anti-smoking campaign was employed.

Furthermore, warning labels on cigarette packages could serve as retrieval cues to remind people of, or reinforce, more elaborate anti-smoking messages that they would be receiving from other sources. ${ }^{77}$ Warning labels would be more effective if they were specifically designed to remind people of antismoking themes they had been exposed to via mass media (for example, television commercials, magazine ads, billboards, etc), point-of-sale displays, and school based programmes. It has been suggested that health campaigns work better when they use multiple media (for example, print, radio, and television) and when a common message is repeated. ${ }^{78}$ If warning labels were coordinated with broader, more extensive campaigns, they would likely have a greater impact on the public. Such broader anti-smoking campaigns, because of the greater space or time available, could also take fuller advantage of the principles of influencing alternative behaviours to smoking, utilising gain-framed messages, emphasising subjective norms, focusing on the relevant attitudes and attitude functions of the target group, and enhancing self efficacy.
As new social psychological principles are identified, these might also be incorporated into broader anti-smoking campaigns. For example, Cialdini has recently formulated a persuasive technique to encourage people to resist an argument that is deceptive or duplicitous. ${ }^{79}$ In his research, Cialdini finds that a persuasive counter-argument that uses aspects of the original advertisement and then counter-argues against it, with an element of ridicule, is most effective. Cialdini has dubbed this technique as the "poison parasite" because it contains two elements, one poisonous (the counter argument) and one parasitic (the mnemonic link to the original argument). An excellent example of this are the "Joe Chemo" ads which directly ridicule and counter-argue the "Joe Camel" ads.† Although such techniques would admittedly be very difficult to incorporate directly onto tobacco packaging, they could be used as part of a ongoing multimedia anti-smoking campaign-cues of which could be contained within a warning label.

\section{RESEARCH TO GUIDE LABEL DEVELOPMENT}

In this paper we have outlined some basic principles from social psychology that could enhance the effectiveness of tobacco warning labels (see fig 5 for a summary of these principles). In some cases, we have offered ways that these specific principles could be operationalised. However, it is clear to us that regardless of the apparent applicability of these social psychological principles, there must be a plan for testing the actual effectiveness of these principles, and for that matter, any other principles that may be relevant in creating a more effective tobacco warning label campaign. We agree with other reviewers of the current research on tobacco warning labels that to be effective, warnings must be continuously developed, tested, targeted, monitored, and revised over time. ${ }^{80}$

To date, research on tobacco warning labels has been somewhat limited (see review by Mitchell ${ }^{2}$ ). There have been studies assessing awareness or recall of existing warning labels, ${ }^{81}$ believability of messages, ${ }^{82}$ and subjective impressions of the effectiveness of existing, new, or proposed warning labels. ${ }^{83}$ But the correlational design of many of the existing studies leads to problems of interpretation.

In one of the best designed study of its kind to date, Borland $^{84} 85$ conducted a longitudinal study in which smokers were surveyed by phone before and six months after new, larger, and enhanced warning labels were introduced in Australia in 1995. In both cross sectional and longitudinal samples, smokers contacted after the new enhanced warning labels had been introduced provided survey responses that were consistent with the notion that the new warning labels had some beneficial effects, including greater likelihood of noticing the health warnings and refraining from smoking on at least one occasion.

There is a need for more powerful research methods to supplement the existing correlational and focus group research and to guide the development of the next generation of labels. We envision a research programme that would employ multiple research methods and contexts, including a combination of laboratory experiments and field studies.

Experimental research would provide a more rigorous test of the possible effectiveness of smoking labels in changing smoking attitudes, beliefs, and behaviours. For example, although the success of mass media anti-smoking campaigns has been well documented, ${ }^{86-88}$ experimental research would allow researchers and tobacco control policy experts alike to isolate the key factors that make such campaigns successful. In addition, although research on message framing has been promising, further research could determine whether it is a

†For the Joe Chemo ads, see http://www.joechemo.org 


\begin{tabular}{|c|c|c|c|c|}
\hline Attract attention & Maintain attention & $\begin{array}{l}\text { Encourage further } \\
\text { elaboration of the message }\end{array}$ & Encourage action & Maintenance \\
\hline $\begin{array}{l}\sqrt{ } \text { Create } \\
\text { noticeable } \\
\text { labels to get } \\
\text { smokers' } \\
\text { attention via } \\
\text { the peripheral } \\
\text { route (e.g. } \\
\text { using size, } \\
\text { colour, } \\
\text { graphics) }\end{array}$ & $\begin{array}{l}\sqrt{ } \text { Include a short, } \\
\text { catchy message } \\
\text { that will hold the } \\
\text { smokers' attention } \\
\sqrt{ } \text { Rotate multiple } \\
\text { messages to avoid } \\
\text { wear-out } \\
\sqrt{\sqrt{ } \text { Utilise gain-and }} \\
\text { loss-framed } \\
\text { messages }\end{array}$ & 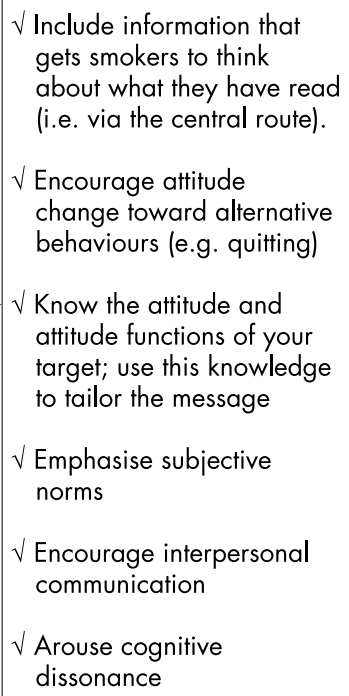 & $\begin{array}{l}\sqrt{ } \text { Include info } \\
\text { designed to } \\
\text { enhance self } \\
\text { efficacy } \\
\sqrt{ } \text { Include info on } \\
\text { how/where to } \\
\text { get help }\end{array}$ & $\begin{array}{l}\sqrt{ } \text { Encourage } \\
\text { those taking } \\
\text { steps to quit or } \\
\text { who have quit } \\
\text { to maintain } \\
\text { self efficacy }\end{array}$ \\
\hline
\end{tabular}

Figure 5 Steps in creating effective smoking labels: a checklist. Although this checklist contains strategies for the creation of effective smoking labels, these labelling strategies may be most effective when supported by a broader anti-smoking campaign that reinforces, elaborates upon, and reminds consumers of these images.

particular type of gain frame that is most persuasive, whether a combination of messages might be most effective, or whether it is the novelty of the message that is important. To get a more realistic picture of the effects of tobacco warning labels, such controlled experiments should involve longer exposure to the labels. We recognise that pragmatic considerations may preclude a full test marketing of potential warning labels per se, but we can envision research that tests the effectiveness of messages that would eventually appear on warning labels in situations other than the warning labels themselves-for example, as part of a health education programme. Although not perfect, such research would provide much needed preliminary data that might help policy makers formulate warning labels (and health education programmes more generally) with greater effectiveness.

As an example of this, before the introduction of the new Canadian warning labels, Health Canada conducted an extensive set of research studies, including experimental studies of the effects of changing certain features of the warning labels (for example, size, presence of photographs). This research provided a powerful empirical base that supported the effectiveness of the new labels and facilitated their implementation.f

Because experimental methods are limited in ecological or external validity, field research could examine the efficacy of tobacco warning labels in the real world. Although experimental techniques are not possible when large scale label campaigns are implemented, natural experiments that utilise a quasi-experimental designs could be employed. One example is the research by Fong and his colleagues (unpublished data) in their quasi-experimental, longitudinal survey of 12000 high school students in Canada and the USA, with survey waves both before and after the introduction of the new Canadian warning labels. Such quasi-experimental

$\ddagger$ These reports are available on the Health Canada website at http://www.hc-sc.gc.ca/hppb/tobacco/bureau/current_research/ index.html research could then be further complemented by more experimental research. That is, if Canada's new warning labels do appear effective in increasing smoking cessation, further experimental research might be utilised to determine more precisely what aspects of the labels are most important (for example, their graphic nature, their novelty, their ability to elicit negative reactions, etc).

Furthermore, social psychological research indicates the benefits of assessing the relevant psychosocial mediators of smoking behaviour-for example, attitudes and intentions toward smoking. When measuring smoking attitudes and intentions, researchers could employ more subtle techniques, because they would reduce the problem of demand characteristics. For example, measures of attitudes and intentions that are embedded within other measures, measures that tap affective responses, and measures that assess consequential behavioural reactions to smokers might be employed. ${ }^{89}$ Furthermore, implicit measures of attitudes (that is, the automatic evaluation associations people have to attitude objects) such as adaptations of the Implicit Association Test ${ }^{90}{ }^{91}$ could be a promising avenue for indirectly tapping into smoking attitudes. Finally, it is important to use theory in guiding research. In this article, we have outlined various principles based on social psychological theory that may aid in the creation of effective smoking labels.

The value of more rigorous research that would evaluate possible public health policies in tobacco control is highlighted by the fact that tobacco companies have spent decades and many millions of dollars creating advertising campaigns that have been found to be extraordinarily effective in creating, maintaining, and expanding their market. They have intimate knowledge about ways to make a product that is inherently unattractive, unappealing, and dangerous to the health of oneself and others into a symbol that is attractive, sexy, appealing, sophisticated, and even associated with healthy activities (for example, Virginia Slims tennis). Cigarette advertising companies developed these techniques through careful research, much of which has utilised the findings and theoretical perspectives of social psychology. Tobacco marketing and advertising campaigns that the public eventually sees 


\section{What this paper adds}

Tobacco warning labels represent a potentially effective method of communicating the health hazards of smoking; moreover, they represent an opportunity for motivating reductions in smoking behaviour. Theory and research in social psychology offers a set of principles that could be used to create more effective warning labels, but to date there has been no review of those relevant social psychological principles as they pertain to tobacco warning labels.

This article represents the first such review. We provide a general description of some important social psychological principles that are relevant not only for the design of warning labels, but also for the design of anti-smoking campaigns more generally.

are the culmination of a long process of experimental research, pilot studies, and extensive field studies. Although tobacco control campaigns seldom have the kind of resources available to them that cigarette advertising campaigns have, it is important to understand that certain aspects of the process of creating an effective advertising campaign of any kind are essential. And the most central aspect of that process is to conduct high quality research to test the effectiveness of possible methods. Social psychological principles-particularly those that are embedded in models of communication-have been shown to be effective in guiding the creation of effective mass media campaigns in tobacco control, ${ }^{92}{ }^{93}$ and have the potential to guide the creation of more effective warning labels.

In closing, there are a number of challenges in designing a more effective set of tobacco warning labels. This article is a first step toward this end. Over the next few years, as we enter a promising time of new opportunities for developing public health campaigns that intend to educate and inform people about the dangers of tobacco use, future campaigns, such as those that will result in the creation of new tobacco warning labels, could be profitably shaped by social psychological principles and informed by research.

\section{ACKNOWLEDGEMENTS}

The preparation of this article was supported by the Centre for Behavioural Research and Program Evaluation of the Canadian Cancer Society/National Cancer Institute of Canada, the Canadian Tobacco Control Research Initiative/Social Science and Humanities Research Council of Canada, the Lyle S Hallman Institute Fund, and the National Cancer Institute of the United States. The authors gratefully acknowledge the contributions of Elizabeth Leal, Tara Elton, Jessica MacKay, Karolina Pajda, and Melissa Kuntz. We would also like to thank two anonymous reviewers for their insightful comments on an earlier draft of this manuscript.

\section{Authors' affiliations}

E J Strahan, G T Fong, M P Zanna, Department of Psychology, University of Waterloo, Waterloo, Ontario, Canada K White, Department of Psychology, University of British Columbia, Vancouver, BC, Canada

L R Fabrigar, Department of Psychology, Queen's University, Kingston, Ontario, Canada

*R Cameron, Department of Health Studies and Gerontology, University of Waterloo

*Also the Centre for Behavioural Research and Program Evaluation, Canadian Cancer Society/National Cancer Institute of Canada

\section{REFERENCES}

1 The World Bank. Curbing the epidemic: governments and the economics of tobacco control. Washington DC: The World Bank, 1999.
2 Mitchell BM. Review of documents on tobacco package warnings and toxic constituent labeling. Report prepared for the Center for Behavioural Research and Program Evaluation, National Cancer Institute of Canada. University of Waterloo, Waterloo, Ontario, Canada: Brenda Mitchell and Associates, 1999.

3 Cialdini RB. Influence: science and practice. 3rd ed. New York: Harper Collins, 1993.

4 Eagly AH, Chaiken S. The psychology of attitudes. Fort Worth, Texas: Harcourt Brace Jovanovich, 1993.

5 Petty RE, Cacioppo JT. The elaboration likelihood model of persuasion. In: Berkowitz L, ed. Advances in experimental social psychology. Hillsdale, New Jersey: Erlbaum, 1986:123-205.

6 Leventhal $\mathbf{H}$. Findings and theory in the study of fear communications. Adv Exp Soc Psychol 1970;5:119-86.

7 Fishbein M. A theory of reasoned action: some applications and implications. In Howe HE, Page MM, eds. Nebraska symposium on motivation. Lincoln, Nebraska: University of Nebraska Press, 1979;27:65- 116.

8 Kahneman D, Tversky A. Prospect theory: an analysis of decisions under risk. Econometrica 1979;47:263-91.

9 Tversky A, Kahneman D. The framing of decisions and the psychology of choice. Science 1981;211:453-8.

10 Rothman AJ, Martino SC, Bedall BT, et al. The systematic influence of gain- and loss-framed messages on interest in and use of different types of health behavior. Pers Soc Psychol Bull 1999;25:1355-69.

11 Schneider TR, Salovey P, Pallonen U, et al. Visual and auditory message framing effects on tobacco smoking. J Appl Soc Psychol (in press).

12 Maheswaran D, Meyers-Levy J. The influence of message framing and issue involvement. J Marketing Res 1990;27:367.

13 Meyerowitz BE, Chaiken S. The effect of message framing on breast self-examination attitudes, intentions, and behavior. J Pers Soc Psychol 1987;52:500-10

14 Rothman AJ, Salovey P, Antone C, et al. The influence of message framing on health behaviour. J Exp Soc Psychol 1993;29:408-33.

15 Banks SM, Salovey P, Greener S, et al. The effects of message framing on mammography utilization. Health Psychol 1995;14:178-84.

16 Kalichman SC, Coley B. Context framing to enhance HIV-antibody-testing messages targeted to African American women. Health Psychol 1995;14:247-54.

17 Detweiler JB, Bedell BT, Salovey P, et al. Message framing and sunscreen use: gain-framed messages motivate beach-goers. Health Psychol 1999;18:189-96.

18 Levin IP, Schnittjer SK, Thee SL. Information framing effects in social and personal decisions. J Exp Soc Psychol 1998;24:520-9.

19 Marteau TM. Framing information: its influence upon decisions of doctors and patients. Br J Soc Psychol 1989;28:89-94.

20 McNeil BJ, Pauker, SG, Sox HC, et al. On the elicitation of preferences for alternative therapies. N Engl J Med 1982;306:1259-62.

21 Wilson DK, Kaplan RM, Schneiderman L. Framing of selections of alternatives in health care. Soc Behav 1987;2:51-9.

22 Robberson MR, Rogers RW. Beyond fear appeals: negative and positive persuasive appeals to health and self-esteem. J Appl Soc Psychol 1988;43:236-47

23 Janis IL. Effects of fear arousal on attitude change: recent developments in theory and experimental research. In: Berkowitz L, ed. Advances in experimental social psychology, vol 3. New York: Academic Press, 1967:166-225

24 Mongeau P. Another look at fear arousing messages. In: Allen M, Preiss $\mathrm{R}$, eds. Persuasion: advances through meta-analysis. Cresskill, New Jersey: Hampton Press, 1998:53-68.

25 Sutton SR. Fear-arousing communication: a critical examination of theory and research. In: Eiser JR, ed. Social psychology and behavioral medicine. New York: Wiley, 1982:303-37

26 Witte K, Allen M. A meta-analysis of fear appeals: implications for effective public health campaigns. Health Educ Behav 2000;27:591-615.

27 Fishbein M, Azjen I. Belief, attitude, intention and behavior: an introduction to theory and research. Reading, Massachusetts: Addison-Wesley, 1975

28 Ajzen I, Fishbein M. Understanding attitudes and predicting social behavior. Englewood Cliffs, New Jersey: Prentice-Hall, 1980

29 Ajzen I, Madden JT. Prediction of goal-directed behavior: Attitudes, intentions, and perceived behavioral control. J Exp Psychol 1986;22:453-74.

30 Finlay KA, Trafimow D, Jones D. Predicting health behaviors from attitudes and subjective norms: between-subjects and within-subjects analyses. J App/ Soc Psychol 1997;27:2015-31

31 Gottlieb NH, Gingiss PL, Weinstein RP. Attitudes, subjective norms and models of use for smokeless tobacco among college athletes: implications for prevention and cessation programming. Health Educ Res 1992;7:359-68.

32 Marcoux BC, Shope JT. Application of the theory of planned behavior to adolescent use and misuse of alcohol. Health Educ Res 1997;12:323-31

33 O'Callaghan FV, Callan VJ, Baglioni A. Cigarette use by adolescents: attitude-behavior relationships. Subst Use Misuse 1999:34:455-68.

34 de Vries $\mathbf{H}$, Dijkstra M, Kuhlman P. Self-efficacy: the third factor besides attitude and subjective norm as a predictor of behavioral intentions. Health Educ Res 1988;3:273-82.

35 van der Plight J, de Vries N. Belief importance in expectancy-value models of attitudes. J Appl Soc Psychol 1998;28:1139-1354.

36 Biglan A, McConnell S, Severson, $\mathrm{HH}$, et al. A situational analysis of adolescent smoking. J Behav Med 1984;7: 109-14. 
37 Presti DE, Ary DV, Lichtenstein E. The context of smoking initiation and maintenance: findings from interviews with youths. J Subst Abuse 1992;4:35-45

38 Maio GR, Olson JM. Emergent themes and potential approaches to attitude function: the function-structure model of attitudes. In: Maio GR Olson JM, eds. Why we evaluate: functions of attitudes. New Jersey: Lawrence Erlbaum Associates, 2000:417-42.

39 Katz D. The functional approach to the study of attitudes. Public Opinion Q 1960;24:163-204.

40 Smith MB, Bruner JS, White RW. Opinions and personality. New York: Wiley, 1956

41 Pryor JB, Reeder GD, Vinacco, JR, et al. The instrumental and symbolic functions of attitudes towards persons with AIDS. J Appl Soc Psychol 1989; 19:377-404

42 Herek GM. Beyond "homophobia": a social psychological perspective on attitudes towards lesbians and gay men. J Homosex 1984;10:1-21.

43 Ennis R, Zanna MP. Attitudes, advertising, and automobiles: a functional approach. Adv Consumer Res 1993;20:662-6.

44 Ennis R, Zanna MP. Attitude function and the automobile. In: Maio, GR, Olson JM, eds. Why we evaluate: functions of attitudes. Hillsdale, New Jersey: Erlbaum, 2000:395-415

45 Belk RW. Materialism: trait aspects of living in the material world J Consumer Res 1985;12:265-80.

46 Belk RW. Possessions and the extended self. J Consumer Res 1988;15:139-68.

47 Belk RW. Extended self and extending paradigmatic perspective. J Consumer Res 1989;16:129-32.

48 DeBono KG. Investigating the social-expressive and value-expressive functions of attitudes: implications for persuasion processes. J Pers Soc Psychol 1987;52:279-87.

49 DeBono KG. On the processing of functionally-relevant consumer information: another look at source factors. Adv Consumer Res 1989;16:312-17.

50 DeBono KG, Packer $M$. The effects of advertising appeal on perceptions of product quality. Pers Soc Psychol Bull 1990;17:197-200.

51 Shavitt S. The role of attitude objects in attitude functions. J Exp Soc Psychol 1990;26: 124-48

52 Snyder M, DeBono KG. Understanding the functions of attitudes: lessons from personality and social behavior. In: Pratkanis AR, Breckler SJ, Greenwald AG, eds. Attitude structure and function. Hillsdale, New Jersey: Lawrence Erlbaum Associates, 1989:339-60.

53 Burnett JJ, Oliver RL. Fear appeal effects in the field: a segmentation approach. J Marketing Res 1979;16:181-90.

54 Bandura A. Exercise of personal agency through the self-efficacy mechanism. In: Schwarzer R, ed. Self-efficacy: thought control of action. Washington DC: Hemisphere Publishing Corp, 1992:3-38.

55 Ajzen I. From intentions to actions: a theory of planned behavior. In Kuhl J, Beckmann J, eds. Action control: from cognition to behavior. Berlin: Springer-Verlag, 1985:11-40.

56 Bandura A. Social cognitive theory and exercise of control over HIV infection. In: DiClemente RJ, Peterson JL, eds. Preventing AIDS: theories and methods of behavioral interventions. New York: Plenum Press, 1994:5-24.

57 Oman RF, Duncan TE. Woman and exercise: an investigation of the roles of social support, self-efficacy, and hardiness. Med Exerc Nutr Health 1995;4:306-15.

58 McAuley E, Courneya KS. Adherence to exercise and physical activity as health promoting behaviors: attitudinal and self-efficacy influences. Appl Prev Psychol 1994;2:65-77.

59 Sullum J, Clark MM, King TK. Predictors of exercise relapse in a college population. J Am Coll Health 2000;48:175-80.

60 Dorsey, AM, Miller KI, Scherer, CW. Communication, risk behavior and perceptions of threat and efficacy: a test of a reciprocal model. J App Commun Res 1999:27:377-95.

61 Lee NK, Oei TPS, Greely JD. The interaction of alcohol expectancies and drinking refusal self-efficacy in high and low risk drinkers. Addiction Res 1999;7:91-102

62 Armitage CJ, Conner M. Distinguishing perceptions of control from self-efficacy: Predicting consumption of a low-fat diet using the theory of planned behavior. J App/ Soc Psychol 1999;29:72-90.

63 Tunstall CD, Ginsberg D, Hall SM. Quitting smoking. Int J Addict 1985;20:1089-112.

64 Bandura A. Social foundations of thought and actions: a social cognitive theory. Englewood Cliffs, New Jersey: Prentice-Hall, 1986.

65 Hafstad A, Aaro LE, Langmark F. Evaluation of an anti-smoking mass media campaign targeting adolescents: the role of affective responses and interpersonal communication. Health Educ Res 1996;1 1:29-38.
66 Festinger L. A theory of cognitive dissonance. Stanford, California: Stanford University Press, 1957

67 Stone J, Aronson E, Crain AL, et al. Inducing hypocrisy as a means of encouraging young adults to use condoms. Pers Soc Psychol Bull 1994:20:1 16-28.

68 Aronson E, Fried C, Stone J. Overcoming denial and increasing the intention to use condoms through the induction of hypocrisy. Am J Public Health 1991;81:1636-8.

69 Chaiken S. Heuristic versus systematic information processing and the use of source versus message cues in persuasion. J Pers Soc Psychol 1980;39:752-66.

70 Chaiken S. The heuristic model of persuasion. In: Zanna MP, Olson JM, Herman $C P$, eds. Social influence: the Ontario symposium, vol 5 Hillsdale, New Jersey: Erlbaum, 1987:3-39.

71 Zuckerman A, Chaiken S. A heuristic-systematic processing analysis of the effectiveness of product warning labels. Psychol Marketing 1998; 15:621-42.

72 Bornstein, RF. Exposure and affect: overview and meta-analysis of research. Psychol Bull 1989;106:265-89.

73 Environics Research Group. Canadian adult and youth opinions on the sizing of health warning messages. Report to Health Canada, 1999.

74 Fischer PM, Krugman DM, Fletcher JE, et al. An evaluation of health warnings in cigarette advertisements using standard marketing research methods: what does it mean to warn? Tobacco Control 1993;2:279-85.

75 Krugman DM, Fox RJ, Fletcher JE, et al. Do adolescents attend to warnings in cigarette advertising? An eye tracking approach. J Advertising Res 1994;39-52.

76 Canadian Cancer Society. Controlling the epidemic - round two and round three; a submission to the Chief, Legislative and Regulatory Processes, Environmental Health Directorate, Health Protection Branch, Ottawa, on amendments to the Tobacco Products Control Regulations as published in the Canada Gazette Part I, 20 March 1993, Ottawa. 16 April 1993.

77 Keller KL. Memory factors in advertising: the effect of advertising retrieval cues on brand evaluations. J Consumer Res 1987:14:316-33.

78 Backer TE, Rogers EM, Sopory P. Designing health communication campaigns: what works? Newbury Park, California: Sage, 1992.

79 Cialdini RB. The poison parasite defense: a new way to sap a competitor's persuasive strength. American Psychological Society, William James Distinguished Lecture at the Annual meeting of the Midwestern Psychological Association (MPA), 2001.

80 Krugman DM, Fox R. Journal of Health Communication 1999;4:95-105.

81 Richards JW, Fischer P, Connor FG. The warning labels on cigarette packages are ineffective. JAMA 1989;261:45

82 Cecil H, Evans RI, Stanley MA. Perceived believability among adolescents of health warning labels on cigarette packs. J Appl Soc Psychol 1996;26:502-19.

83 Linthwaite P. Health warnings. Health Educ J 1985;44:218-19.

84 Borland R. Tobacco health warnings and smoking-related cognitions and behaviours. Addiction 1997;92:1427-35

85 Borland R, Hill D. Initial impact of the new Australian tobacco health warnings on knowledge and beliefs. Tobacco Control 1997;6:317-25.

86 Hafstad A, Aaro LE, Langmark F. Evaluation of an anti-smoking mass media campaign targeting adolescents: the role of affective responses and interpersonal communication. Health Educ Res 1996;1 1:29-38.

87 Hu T, Sung HY, Keeler TE. Reducing cigarette consumption in California: tabocco taxes vs. an anti-smoking media campaign. Am J Public Health 1995:85:1218-22.

88 Jenkins CN, McPhee SJ, Le A, et al. The effectiveness of a media-led intervention to reduce smoking among Vietnamese-American men. Am J Public Health 1997;87:1031-4.

89 Towson SMJ, Pepperall G, Zanna MP. The impact of a smoking prevention program on the evaluation of smokers and non-smokers. Presented at the annual meeting of the Canadian Psychological Association, Ottawa, 1984. Abstract published in Canadian Psychology 1984;25:487.

90 Swanson JE, Rudman LA, Greenwald, AG. Using the Implicit Association Test to investigate attitude-behaviour consistency for stigmatized behaviour. Cognition Emotion 2001;15:207-30.

91 Greenwald AG, McGhee DE, Schwartz JLK. Measuring individual differences in implicit cognition: the Implicit Association Test. J Person Soc Psychol 1998;74:1464-80.

92 Atkin, CK, Wallack, L. Mass communication and public health complexities and conflicts. London: Sage, 1990.

93 Rice, RE, Atkin, CK. Public communication campaigns. London: Sage, 1989. 